\title{
INHALATION TESTS OF BRONCHIAL HYPERSENSITIVITY IN POLLEN ASTHMA
}

\author{
BY \\ K. M. CITRON, A. W. FRANKLAND, AND J. D. SINCLAIR* \\ From the Institute of Diseases of the Chest, Brompton Hospital, and the Allergy Department, \\ Wright Fleming Institute, St. Mary's Hospital, London
}

(RECEIVED FOR PUBlication MARCh 17, 1958)

Possible allergic causes of asthma are frequently investigated by determining the sensitivity of the skin to various extracts of potentially allergenic substances, but the results of skin tests may correlate poorly with other clinical indications of specific allergies. Bronchial sensitivity cannot always be inferred from skin sensitivity. Determination of the response of the bronchi to allergens introduced directly into the respiratory tract seems to be a more direct method of testing for allergic causes of asthma, since it tests the hypersensitivity of the bronchial tree which is responsible for the symptoms in asthma and simulates the usual mode of entry of the allergen as it occurs in asthma. Inhalations of allergens were found by Colldahl (1952) to produce wheezing, evident to the subject or to observers, in some asthmatics, and by Herschfus, Rubitsky, Beakey, Bresnick, Levinson, and Segal (1951), Schiller and Lowell (1952) and Herxheimer (1952) to produce changes in the spirogram.

The object of this investigation was to try out inhalation tests of bronchial hypersensitivity and to determine whether they give results which are reliable, consistent, and specific. For this purpose we selected patients in whom asthma was strictly seasonal and clinically appeared to be due only to grass pollen. We gave them inhalations of grass pollen extract and assessed the bronchial response by spirometry, and studied the effect upon this response of pollen hyposensitization treatment.

\section{Clinical Material}

The 19 patients selected gave a history of asthma occurring only in the grass pollen season. All had positive skin responses to a mixed grass pollen extract in a dilution of 1:1,000 using the prick method (Frankland and Augustin, 1954). The duration of the asthma ranged from one to 20 seasons (mean seven

\footnotetext{
* Wunderly Travelling Scholar of the Royal Australasian College of Physicians.
}

seasons). The patients' ages ranged from 16 to 68 years (mean 32 years). Each patient was tested on two separate occasions in early March and at the end of May before the beginning of the grass pollen season, at which time all were free of asthma. In the interval between the two tests 14 patients received a course of pollen hyposensitization. Ten received a course of injections up to 18,000 Noon units of a mixture of Timothy (Phleum pratense) and Cocksfoot (Dactylis glomorata) grass pollen extract (Frankland 1955), and four received lower doses. The remaining five patients had no injections and served as controls. All patient kept charts on which they entered a daily record of their symptoms throughout the subsequent pollen season, and each patient was interviewed at the end of the season.

\section{METHOD}

The bronchial reaction to the pollen inhalation was detected by measuring change in the forced expiratory volume in 1 second (F.E.V.1.0), previously termed "timed vital capacity" (Gandevia and Hugh-Jones, 1957). The patients inspired fully, then expired as rapidly and completely as possible into a light recording spirometer of the type described by Bernstein, D'Silva, and Mendel (1952). The development of obstruction to the airway, for example, by spasm or oedema, slows the expiration, particularly in the early period. We have found the F.E.V.1.0 a simple, repeatable, and sensitive test of such obstruction. The patient was instructed in the technique of the forced vital capacity (F.V.C.) and after a little preliminary practice three recordings were made. A Bright Smith's nebulizer was used to produce aerosols for inhalation using a constant rate of flow of oxygen of 8 litres per minute. The patient first inhaled Coca's solution (Coca, Walzer, and Thommen, 1931), the extracting fluid of the pollen extract, after which three more recordings of F.V.C. were made. The patient was then given an inhalation of mixed grass pollen, 10,000 Noon units $(1 \%$ w./v.) in Coca's fluid. This was inhaled for two minutes, but because of systemic reactions in some patients this was reduced to one minute in some later cases. The same duration of inhalation was given in both first and second tests. The F.V.C. was recorded at intervals thereafter until 

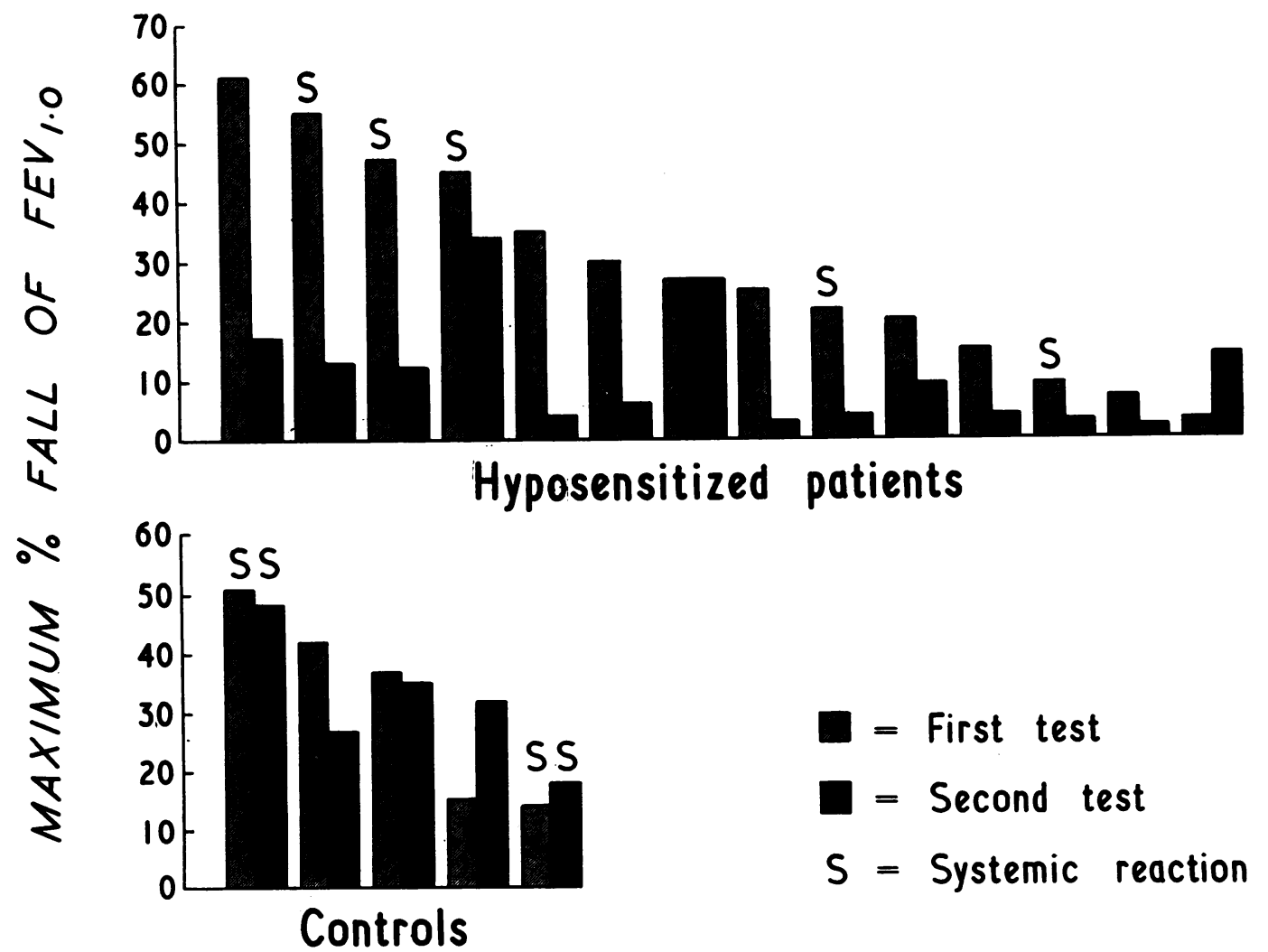

Fig. 1. - The results of the first inhalation test in each patient are shown in the grey columns, which depict the maximum fall of

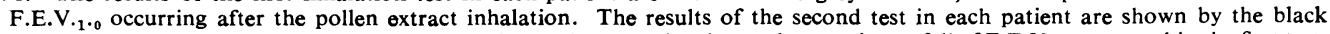
columns, which depict the fall of F.E.V. $\cdot_{1 \cdot 0}$ occurring at the same time interval as maximum fall of F.E.V. $\cdot_{1 \cdot 0}$ occurred in the first test.

there was clear evidence of a fall of F.E.V.1.0 or until the end of 15 minutes. If a reaction occurred $1 \%$ isoprenaline was given by inhalation and further records of the F.V.C. were made during recovery. Those patients who developed asthma or systemic reactions to the inhalation were not permitted to leave the clinic until fully recovered, and were given a supply of isoprenaline tablets to take away with them. Adrenaline, aminophylline, and oxygen were available in case of severe reactions, and all tests were made by medical staff.

The F.E.V.1.0 was measured from the various F.V.C. tracings. Comparison of F.E.V.1.0 before and after the control (Coca's solution) inhalation was used to measure the variation of F.E.V.1.0 in each subject. The mean variation was $4 \%$, ranging between $-10 \%$ and $+11 \%$. Only two of 19 patients showed a fall of more than $8 \%$. A fall in the mean value of the three measurements of F.E.V.1.0 after pollen extract inhalation compared with that after the control inhalation was used as an index of expiratory obstruction, this fall being considered significant only if it exceeded any obtained following the control solution in the individual patient.

\section{RESUlTS}

The results are summarized in Fig. 1, which shows for each patient the results of the first test in March and the second test in May. In the first test, shown in the grey columns, the maximum fall of F.E.V.$_{.1 .0}$ after the pollen extract inhalation is recorded. In the second test, shown in the black columns, the fall of F.E.V.V ${\cdot \cdot^{\cdot} 0}_{0}$, at the same time interval as the maximum fall of F.E.V. ${\cdot{ }_{1} \cdot{ }_{0}}$ in the first test, is recorded. Only figures at this time could be used for comparison, because in the first test isoprenaline was usually administered at this time while the F.E.V..$_{1} \cdot{ }_{0}$ might still be falling.

The patients are divided into two groups: those who received hyposensitization treatment and those who did not and thus served as controls.

First Bronchial Sensitivity Tests.-The F.E.V..$_{1.0}$ fell in 18 of the 19 patients tested. They had a fall of F.E.V ${ }_{\cdot 1 \cdot 0}$ after the pollen extract which was greater than that due to the control inhalations, and ranged from $7 \%$ to $61 \%$. A 
mean fall of $31 \%$ took place in a mean time of seven minutes after inhalation of the pollen extract. In 13 of the 18 patients the reaction was accompanied by asthma evident to the subject and also evident to the observer in six. Wheezing was rapidly relieved by prompt inhalation of isoprenaline. However, five patients in whom wheezing had been relieved by isoprenaline had a recurrence of asthma later, for two nights in three patients and up to one week in two patients.

Nasal symptoms, consisting of itching and sneezing, occurred in five patients, and resembled the hay fever which they had suffered in the previous pollen season. Seven patients developed systemic reactions within five minutes of the inhalation. Symptoms included flushing of the face followed by pallor, faintness, nausea, and tachycardia. These symptoms appeared to be anaphylactic in nature and were probably due to absorption of the pollen extract through the bronchial mucosa. They passed off within a few minutes of inhaling isoprenaline.

Second Bronchial Sensitivity Test.-Among the 18 patients who showed bronchial sensitivity in the first test in March, 13 were hyposensitized and five were not and served as controls, and all were tested again in May.

Twelve of the 13 patients who reacted in the first test and were hyposensitized showed a reduced bronchial reaction in the second test compared with that in the first test. The mean fall in F.E.V..$_{1 \cdot 0}$ was only $11 \%$ compared with $31 \%$ before hyposensitization. In contrast to the frequency of symptoms in the first test no patient had asthma evident to the observer, none had recurrent wheezing after the test, and only one had nasal symptoms. No patient had a systemic reaction ; five had had one in the first test.

The five control patients who had not been hyposensitized showed no consistent change in bronchial reaction in the second test compared with the first (Fig. 1). The mean fall of F.E.V.$_{1 \cdot 0}$ was $32 \%$ in both the first and the second tests. Chest symptoms were similar to those occurring in the first test, and systemic reactions recurred in the two patients who had had them previously.

\section{Discussion}

The presence of bronchial hypersensitivity to pollen has been confirmed in this group of seasonal asthmatics. The degree of bronchial hypersensitivity varied widely in individual patients. The average bronchial response of a group of patients with the most severe asthma was greater than that of less severe asthmatics, and was greater for a group of asthmatics who had had asthma for a longer time compared with those who had suffered for a shorter time, but the differences between these small groups did not attain statistical significance. Bronchial sensitivity did not match quantitatively with skin sensitivity to pollen nor did skin sensitivity correlate quantitatively with the clinical manifestations of pollen asthma. Systemic reactions which occurred in about one-third of the patients tested did not appear to correlate with either the severity of the bronchial response or the clinical severity of the asthma.

Fall in degree of bronchial hypersensitivity as assessed from the results of the first and second rests correlated well with the patients' symptoms in the subsequent pollen season. Thirteen patients, whose bronchi reacted to pollen inhalation, were hyposensitized, and 12 showed a fall in bronchial response in the second test. In the subsequent pollen season all 13 did well; nine were completely free of asthma and four were considerably improved. Of controls, five patients who were not hyposensitized had the usual asthma in the subsequent season. $A$ fall in the bronchial sensitivities was, therefore, usually correlated with successful hyposensitization.

One patient began seasonal asthma at the age of 40 years and his skin reacted to pollen. Unlike all the other subjects he showed no response to the first inhalation test, but after attempted hyposensitization he did so, and wheezed for 24 hours after the test. Moreover, he was the only patient in whom hyposensitization did not result in considerable symptomatic relief in the subsequent pollen season. Thus, although clinically he appeared to have pollen asthma, his asthma was evidently of a different nature from that of the other patients and the bronchial sensitivity tests picked him out as differing from the other patients.

Three criteria must be fulfilled in order that the inhalation test can be relied upon to give reliable information. First, the bronchial response to the test must be consistent. Secondly, it must be specific. Thirdly, no non-specific reaction must occur. The general similarity of responses to the two tests at three months' interval in the control group has confirmed the consistency of the reaction. The responses of the pollen asthmatics to the inhalations and the good correlation with successful hyposensitization has confirmed that the test elicits specific bronchial hypersensitivity. A separate group of 12 asthmatics, who had no history of pollen asthma, gave no bronchial reaction to pollen extract inhalations. This has con- 
firmed that the inhalations do not cause nonspecific bronchial reactions.

We have found that the bronchial inhalation test with pollen extract is more reliable than skin tests with pollen in eliciting the clinical significance of pollen in asthmatic patients. For instance, five asthmatic patients had positive skin reactions to pollen but no history of seasonal asthma, and pollen extract inhalations gave no reactions. Another two patients had negative skin tests to pollen but a seasonal incidence of symptoms suggesting pollen asthma; in these, pollen extract inhalation tests were positive.

Our observations lead us to conclude that inhalation tests may give qualitative and quantitative information about specific bronchial hypersensitivities in asthma. It is possible that such information might be helpful in the management of certain cases of asthma and further work is in progress to determine the place of this technique in clinical practice.

\section{SUMmary}

A technique for measuring bronchial hypersensitivity in grass pollen asthma by determining forced expiratory volumes after grass pollen extract inhalations is described. The test was found reliable in eliciting specific bronchial reactions in asthmatics in whom asthma was due to grass pollen and did not produce non-specific reactions in asthmatics in whom asthma was due to other causes. The intensity of response was generally consistent in individual patients, and diminution of response to the inhalation test was usually associated with successful hyposensitization treatment.

We thank Dr. J. G. Scadding and Dr. J. Pepys for their advice. Duncan Flockhart and Co. Ltd. supplied the pollen extracts for the inhalation tests. We are grateful to the patients in this investigation for their co-operation.

\section{REFERENCES}

Bernstein, L., D'Silva, J. L., and Mendel, D. (1952). Thorax, 7, 255 Coca, A. F., Walzer, M., and Thommen, A. A. (1931). Asthma and Hay Fever in Theory and Practice. Thomas, Springfield, Ill.

Colldahl, H. (1952). Acta allerg. (Kbh.), 5, 133.

Frankland, A. W. (1955). Int. Arch. Allergy, 6, 45. and Augustin, R. (1954). Lancet, 1, 1055.

Gandevia, B., and Hugh-Jones, P. (1957). Thorax, 12, 290.

Herschfus, J. A., Rubitsky, H. J., Beakey, J. F., Bresnick, E. Levinson, L., and Segal, M. S. (1951). Int. Arch. Allergy, 2, 97.

Herxheimer, H. G. J. (1952). The Management of Bronchial Asthma, $A$ Guide to Treatment. Buttorworth, London.

Schiller, I. W., and Lowell, F. C. (1952). J. Allergy, 23, 234. 